\title{
The social relevance and social impact of knowledge and knowing
}

\section{Special Issue Editors:}

\section{Giuseppe Scaratti}

Faculty of Economics, Università Cattolica del Sacro Cuore, Milan, Italy giuseppe.scaratti@unicatt.it

\section{Mara Gorli}

Faculty of Education, Università Cattolica del Sacro Cuore, Milan, Italy mara.gorli@unicatt.it

\section{Laura Galuppo}

Faculty of Psychology, Università Cattolica del Sacro Cuore, Milan, Italy laura.galuppo@unicatt.it

\section{Silvio Ripamonti}

Faculty of Psychology, Università Cattolica del Sacro Cuore, Milan, Italy silvio.ripamonti@unicatt.it

\section{Caterina Gozzoli}

Faculty of Psychology, Università Cattolica del Sacro Cuore, Brescia, Italy caterina.gozzoli@unicatt.it

The proposed Special Issue aims to explore a challenge currently present in the academic worldpursuing the social relevance of knowledge.

The concept of the relevance of knowledge and the relationship between theory and practice has been widely addressed and discussed, for example, in a number of journal Special Issues including Organization Studies (2009 and 2010), the Journal of Management Studies (2009), and the British Journal of Management (2011). In the search to balance "scientific rigour" with "practical relevance" (Eikeland and Nicolini, 2011), various modes of knowledge have been proposed: Mode 1 scientific, Mode 2 contextual (Gibbons et al., 1994), Mode 3 diverse stakeholders (Huff and Huff, 2001), and Mode 0 patronage (Bresnen and Burrell, 2012). The question lying at the heart of this debate seems to be whether organization studies has anything meaningful and relevant to say (Alvesson, 2012).

This question of the relevance of research has recently been considered as the outcome of a research process founded on the co-generation of knowledge, as emerging in the tradition of action research 
(see Cassell and Johnson, 2006; Reason and Bradbury, 2001), collaborative processes (Shani et al., 2008), and on generative dialogue between practitioners and academics who share the design and evaluation of a research effort.

While this proves to be extremely useful for framing academic attention to knowledge and the practical impact of research in organizational contexts, it could be widened. This Special Issue proposal links with this literature on the co-production of knowledge, but also aims to extend the debate to the concept and practice of social value and social relevance, and their impact on different ways of knowing, researching, and learning in organizations and in complex contexts and systems.

In order to explain what social value means, we propose different features of the definition of the word "social":

- A first meaning highlights the dialogical and emergent ongoing process of knowledge generation: social is what happens within a co-creation process made by people in inter-relation (groups, organizations, communities) in order to give sense to their daily working life.

- A second meaning relies on the cultural dimension of values, rules, collective identity that nurture the reciprocal influence between organizational context and its environment. Social in this case refers to the symbolic system diffused and implicit in a specific context.

- A third meaning refers to the constant process of production and reproduction of situated systems of activity, triggering discussion, interactions, and conflict dynamics by which people shape what they consider as intelligible, suitable, and actionable in their context. Social in this case is connected with the organizational aesthetics and ethics, distributed and circulating in a specific context, facing to material and immaterial aspects of knowledge.

- A fourth meaning relates to the plurality of voices, powers, and interests that can be listened to and safeguarded. The social here points out the relevance of the engagement and involvement of different stakeholders who contribute through various levels of participation and who have a stake in the knowledge generated. This claim links directly to certain methodological approaches that take into account the possibility to research through multi-vocality and multiperspectives processes (action research, collaborative research, participative inquiry, etc.).

- A fifth meaning refers to the social capital and social impact generated by the organizational system while pursuing productive goals. Organizational processes may sustain and nurture trust, availability, involvement, and collaboration as collateral functions for any kind of production or social achievement. The term "societal value" or "shared value" (Porter and Kramer, 2011) is an issue that many companies are now concerning themselves with, pushing for new conceptualizations and research directions.

The different meanings of social express the idea that socially relevant knowledge and learning implies attention to plural dimensions made by subjectivities and inter-subjectivities, organizational and contextual aspects. Indicators, outcomes, effects, and consequences of knowledge generation should therefore be searched in the practical implications and in the actual meaning shaped in the sociality.

Regarding the concept of relevance, many works in literature describe and define research processes as relevant, but do not consider the details of the social side of such a relevance. Furthermore, in most cases, theoretical rather than empirical papers are the ones addressing the relevance debate. Fewer contributions therefore provide clear indicators highlighting whether, how and to whom the knowledge produced is relevant for. In other words, the "practice" of generating a socially relevant research still remains under explored. 
This Special Issue encourages contributions that explore and make visible how, in practice, socially relevant knowledge is generated. Papers may therefore focus on the following: What is the nature of social relevance and value in relation to knowledge? How can we "practice" a process of knowledge generation and learning, which could be recognized as "socially relevant" knowledge? Which indicators and criteria help evaluate such a process and its outcomes as socially relevant? How can we testify to the relevance of the knowledge produced? What kind of tools, processes, methods, and clues may be made visible in pursuing relevant knowledge (related to artifacts, practices, discourses, conversations, etc.)?

\section{Type of submissions invited}

The proposed Special Issue invites contributions, either conceptual or empirical, which develop the understanding of social relevance and social value in knowledge production and in learning.

We invite submissions that address questions such as the following:

- Should we be concerned with social relevance?

- What different voices need to be listened to, in order to claim that there is a relevant impact of the knowledge produced?

- What practices may be used to approach the multiplicity and plurality of voices necessary to testifies the social relevance resulting in a knowledge process?

- What kind of strategy is possible to use for detecting and making visible social relevance and social value?

- How practices, discourse, and artifacts are used as objects of reflections regarding the social relevance produced?

- If relevance is also associated to a process of knowledge co-generation, how can we trace the specific features of this process?

- What responsibilities researchers and practitioners must take for making knowledge "socially relevant"?

- Social, societal, and shared value: how to critically deal with these concepts?

- Social relevance and/or social impact: which are the differences, which are the connections?

These are suggested topics only. Other new perspectives and/or topics are welcome, and critical perspectives are encouraged.

\section{References}

Alvesson M (2012) Do we have something to say? From re-search to roi-search and back again. Organization 20(1): 79-90.

Bresnen M and Burrell G (2012) Journals à la mode? Twenty years of living alongside Mode 2 and the new production of knowledge. Organization 20(1): 25-37.

Cassell C and Johnson P (2006) Action research: Explaining the diversity. Human Relations 59(6): 783-814.

Eikeland O and Nicolini D (2011) Turning practically: Broadening the horizon. Journal of Organizational Change Management 24(2): 164-174.

Gibbons M, Limoges C, Nowotny H et al. (1994) The New Production of Knowledge: The Dynamics of Science and Research in Contemporary Societies. London: SAGE.

Huff AS and Huff JO (2001) Re-focusing the business school agenda. British Journal of Management 12: S49-S54. Porter ME and Kramer MR (2011) Creating shared valued. Harvard Business Review 89(1-2): 62-77.

Reason P and Bradbury H (2001) Handbook of Action Research. London: SAGE.

Shani AB, Mohrman SA, Pasmore WA et al. (2008) Collaborative Management Research. London: SAGE. 